\title{
Modelling flow dynamics in water distribution networks using artificial neural networks - A leakage detection technique
}

\author{
Eugine Makaya, ${ }^{* 1}$ and Oliver Hensel ${ }^{1}$ \\ ${ }^{{ }^{*}}$ Department of Agricultural Engineering, University of Kassel, 37213 Witzenhausen, GERMANY \\ ${ }^{2}$ Department of Agricultural Engineering, University of Kassel, 37213 Witzenhausen, GERMANY \\ "Corresponding Author's e-mail: eugine.makaya@gmail.com Tel. +263773208002
}

\begin{abstract}
Computational approaches can be used to detect leakages in water distribution networks. One such approach is the Artificial Neural Networks (ANNs) technique. The advantage of ANNs is that they are robust and can be used to model complex linear and non-linear systems without making implicit assumptions. ANNs can be trained to forecast flow dynamics in a water distribution network. Such flow dynamics can be compared with water demands in a particular district metered area. The objective of this study was to model flow dynamics in four district metered areas of the City of Harare, Zimbabwe using the ANNs technique in an effort to detect systems leakages. A multi-layer feed-forward back-propagation artificial neural network was used for modelling the flow and simulate water demand using a Matlab Neural Network Toolkit. The difference between actual water consumed (metered consumption) and the simulated water demand for a district metered area represents the water leakage in the water distribution network of the district metered area. It was discovered that an ANN could be trained and be used to forecast flow with up to $99 \%$ confidence. Thus, ANNs technique is a flexible and efficient approach to detection of leakages in water distribution networks.
\end{abstract}

Keywords: Artificial neural network; Leakage detection technique; Water distribution; Leakages

DOI: http://dx.doi.org/10.4314/ijest.v7i1.4

\section{Introduction}

Water resources are under immense pressure due to population explosion and industrialisation. The pressure on water resources is exacerbated by the fact that water is a finite resource, whose management should be done to ensure that the least of it is lost. Furthermore, the problem of limited water resources is worsened by water losses in the distribution mains. In developing countries more than $40 \%$ of the treated water is lost as non-revenue water (McKenzie, 1999). Leakage is one such way by which water is lost from the water distribution network. For the City of Harare, an average of $36 \%$ of the total water loss is lost through leakage. Blantyre water board is losing $72 \%$ of the $52 \%$ non-revenue water as real losses (Chiipanthenga, 2008; Chipwaila, 2009). Leakage is a function of pipe age, pipe material type, pressure, soil type as well as pipe laying workmanship. However, pressure plays a leading role in enhancing leakage. According to Chiipanthenga (2008), by reducing pressure by $20 \%$, leakages were decreased by $30 \%$. Pressure in any water distribution network is directly related to the flow of water in the network. The International Water Association (IWA) water loss taskforce proposed four basic leakage management activities for leakage reduction; which are: (i) pressure management (ii) active leakage control (iii) speed and quality of repair, and (iv) pipeline asset management, maintenance and renewal (Lambert and McKenzie, 2002). From the leakage management activities pressure variations play a major role. The rate of leakage in water distribution networks is a function of pressure applied by pumps or by gravity head (McKenzie, 2001). Maggs (2005) also indicated that the frequency of new pipe bursts is a function of pressure. On the other hand, Marunga et al. (2006) in studies that were undertaken in Zimbabwe found that a pressure reduction from $80 \mathrm{~m}$ to 
$50 \mathrm{~m}$ resulted in a $40 \%$ reduction in minimum night flows, and that further reductions of pressure resulted in further reduction in minimum night flows. Research has also shown that pressure is directly related to flow in a water distribution network.

Water loss management has become a key priority for water utilities in many countries. However, water loss management has not been an easy task for many water managers. This is because of the complex nature of the water distribution networks and complex water demand dynamics. The complexity of the water distribution networks is worsened by the fact that some networks are very old and have been altered several times such that the network structures are not understood by the water managers. Thus, water distribution networks can be very complex systems whose orientation is difficult to model using linear programming. Puust, et al., (2010) gave a profound overview of different techniques for managing background leakage in distribution systems, as well as detecting pipe bursts. With the exponential growth of computer power which has allowed easy tackling of ever larger and more complex problems, computational fluid dynamics has become an established discipline (Ferziger and Peric, 1996). Marunga et al., (2006) used EPANET hydraulic modelling software to model pressure distribution for the highest and lowest points in a distribution system of the City of Mutare, Zimbabwe. Although good results were obtained, the efficiency of EPANET like any other software depends of the accuracy of the input data. Bakker et al., (2003) developed an algorithm which compared measured and predicted water demands to detect pipe bursts. The algorithm proved to be able to detect bursts where the water loss exceeds $30 \%$ of the average water demand in the area. However, the water loss threshold of $30 \%$ was rather too high, hence the need for a more robust and more efficient approach. Thus, in general, smaller leakages will stay unnoticed for much longer period. To detect smaller leakages more flow meters should be installed in the distribution network at higher monitoring frequency.

Water utilities rely on water main break prediction models to prioritize the rehabilitation and replacement of their water main assets. These models typically utilize pipe, trench, and historical break data to predict the break rate of water mains in a network (Kleiner and Rajani, 2001). A number of statistically-based water main prediction models have been developed in the last 30 years. The statistical models are developed with historical data on pipe breaks to identify failure patterns, and they extrapolate these patterns to predict future pipe breaks. Financial costs to repair and replace these water mains are estimated to exceed $\$ 1$ billion annually in Canada alone (Tesfamariam et al., 2006). Soft computing models, which are a type of statistical models, also use historical data to exploit the tolerance of imprecision, uncertainty, and partial truth (Zadeh, 1994). Soft computing includes fuzzy techniques, artificial neural networks (ANNs), genetic algorithms (GA), and probabilistic and evidential reasoning. ANNs are mimicry of biological neural systems that recognize and learn patterns through interactions with the environment (Jafar et al., 2010). ANN models have been applied in a number of engineering research fields (Al-Barqawi and Zayed, 2008). Several researchers have developed ANN models to predict water main failures (Achim et al., 2007; Ahn et al., 2005, Al-Barqawi and Zayed, 2008; Jafar et al., 2010 and Asnaashari et al., 2013). ANN models provide a means of analysing the interactions between static, environmental and operational factors of the water distribution system (Nishiyama and Filion, 2013). Mounce et al., (2003), Mounce and Machell (2006), Mounce and Boxall (2010) and Mounce et al. (2011) described the application of ANNs combined with fuzzy logic to evaluate pressure and flow measurements. In Mounce et al. (2011) the application of the system in practise in a six month test period was described. It was proved that the system was able to detect 7 of 18 reported bursts, where the system generated a total of 46 alerts. The advantage of ANNs over the traditional approaches is that ANNs have the ability to model linear and non-linear systems without the need to make assumptions implicitly as in most traditional statistical approaches (Al Shamisi et al., 2011).

An artificial neural network is composed of a network of neurons and takes the cue from their biological counterparts, in the manner that neurons being capable of learning can be trained to find solutions, recognise patterns, classify data and even forecast future events. ANNs have found wide application in simulating very complex relationships and as such found wide application in modelling water resources management problems including leakage detection, water distribution network optimisation, water pipeline replacement and rehabilitation, water demand forecasting, and pressure monitoring (Bakker et al., 2003). Such a network is usually made up of many layers arranged in series, each layer containing one or a group of neurons each of which have the same pattern of connections to the neurons in the other layer (Shamseldin, 1997). The first and last layers are used for input and output variables and the intermediate layers are usually connoted as hidden layer which can be one or many, depending on the complexity of the problem. The weights to the neurons are automatically adjusted by training the network according to a specified learning rule until it properly simulates the past data or performs the desired test. Mathematical functions, known as neuron transfer functions, are used to transform the input to output for each neuron. The log-sigmoid transfer function is commonly used for hidden layer neurons; especially with the back propagation algorithm (The Mathworks Inc., 2002). Back propagation algorithms are based on multi-layered feed forward topology with supervised learning. In order to train a neural network to perform some task, the weights of each unit are adjusted in such a way that the error between the desired output and the actual output is reduced. This process requires that the neural network compute the error derivative of the weights (E). In other words, it must calculate how the error changes as each weight is increased or decreased slightly. The back propagation algorithm is the most widely used method for determining E. There is a real number associated with each connection, which is called the weight of the connection. It is then convenient to represent the pattern of connectivity in the network by a weight matrix $\mathrm{W}$ whose elements are the weights in W. Two types of connections are usually used; the excitatory and inhibitory connection. An optimisation algorithm is used to select the control input that optimises future performance (Nishimaya and Filion, 2013).

The Multi-layer Perception Neural Network (MLP) is a network in which there is an input layer consisting of nodes that simply accept the input values. The outputs of neurons in a layer are inputs to neurons in the next layer. The last layer is called the 
output layer. Layers between the input and output layers are known as hidden layers. With the exception of the input neurons, there are two separate steps involved in the retransformation of inputs to outputs for neurons in a network (Parida et al, 2006).

Step 1 .

Each neuron in a layer receives a summation of weighted activations from all neurons in the preceding layer of inputs to the network. A constant term, usually referred to as neuron threshold value is added to this summation to yield the net input, $Y_{\text {nef }}$, to the neuron;

$$
Y_{n e t}=\sum_{i=1}^{N} Y_{i} W_{i}+W_{0}
$$

where $N$ is the total number of neurons in the preceding layer or input array,

$Y_{i}$ is the neuron input received from the $i^{\text {th }}$ neuron in the preceding layer or input array,

$W_{i}$ is the connection weight or strength of the neuron to an $i^{\text {th }}$ neuron in the preceding layer or input array, and

$W_{o}$ is the neuron bias/threshold value.

For a linear output, a bias term is equivalent to an intercept in a regression model. A bias term can be treated as a connection weight from a special unit with a constant value of negative one. Depending on the terminology, whether bias or thresholds are added or subtracted, the performance of the network may generally not be affected depending on the transfer function.

Step 2.

The second stage entails transformation of the net input, $Y_{\text {net }}$, into output, $Y_{\text {out }}$,

$$
Y_{\text {out }}=f\left(Y_{n e t}\right)=f\left(\sum_{i=1}^{N} Y_{i} W_{i}+W_{0}\right)
$$

where $f($.$) denotes the selected neuron transfer function.$

There is no rule of thumb on determining the number of hidden layers and neurons in such layers, and thus the design and comparisons of different network architectures from the same data sets seems the best option in obtaining an optimum network structure. The strategy of selecting the optimal number of hidden layer(s) is through varying the number of neurons, hidden layers and training functions.

Despite all the past advances in water distribution systems flow modelling and leakage detection methods, there is still need to further improve the efficiency and reliability of these methods. There is need to develop new and more effective leakage detection methodologies. Therefore, due to the shortfalls of other conventional approaches to model complex systems with complex flow dynamics, ANNs are the most convenient approaches for such systems. The objective of this study was to model flow dynamics in a water distribution network using ANNs in order to assess the level of water being lost through leakage. Thus, the purpose of the work was to explore the capabilities of ANN approaches in simulating flows in water distribution networks for the sake of detecting systems leakages. In this study four district metered areas (DMAs) of the City of Harare, Zimbabwe were used for calibration and validation of the model. Flows into the DMA were used as input data for water supply simulations.

\section{Study area}

A case study of the City of Harare, Zimbabwe was used in this study. Figure 1 shows the location of the City of Harare and the selected four DMAs. The four DMAs are Budiriro (25 years old), Glenview (36 years old), Belvedere (45 years old) and Mabelreign (50 years old) respectively, in the order of the age of the water distribution network. The frequency of pipe bursts is highest in Mabelreign and least in Budiriro. The choice of these areas was based on reliability of water supply to these DMAs. The four DMAs have about 27600 connections, serving a population of about 138300 people. The average volume of water supplied to the four DMAs is about $2,500,000 \mathrm{~m}^{3} /$ month. The age of the pipe network ranges between 25 years and 50 years. The water supply situation for the study area is aggravated by leakages averaging $36 \%$ of total water production (City of Harare, 2011). 

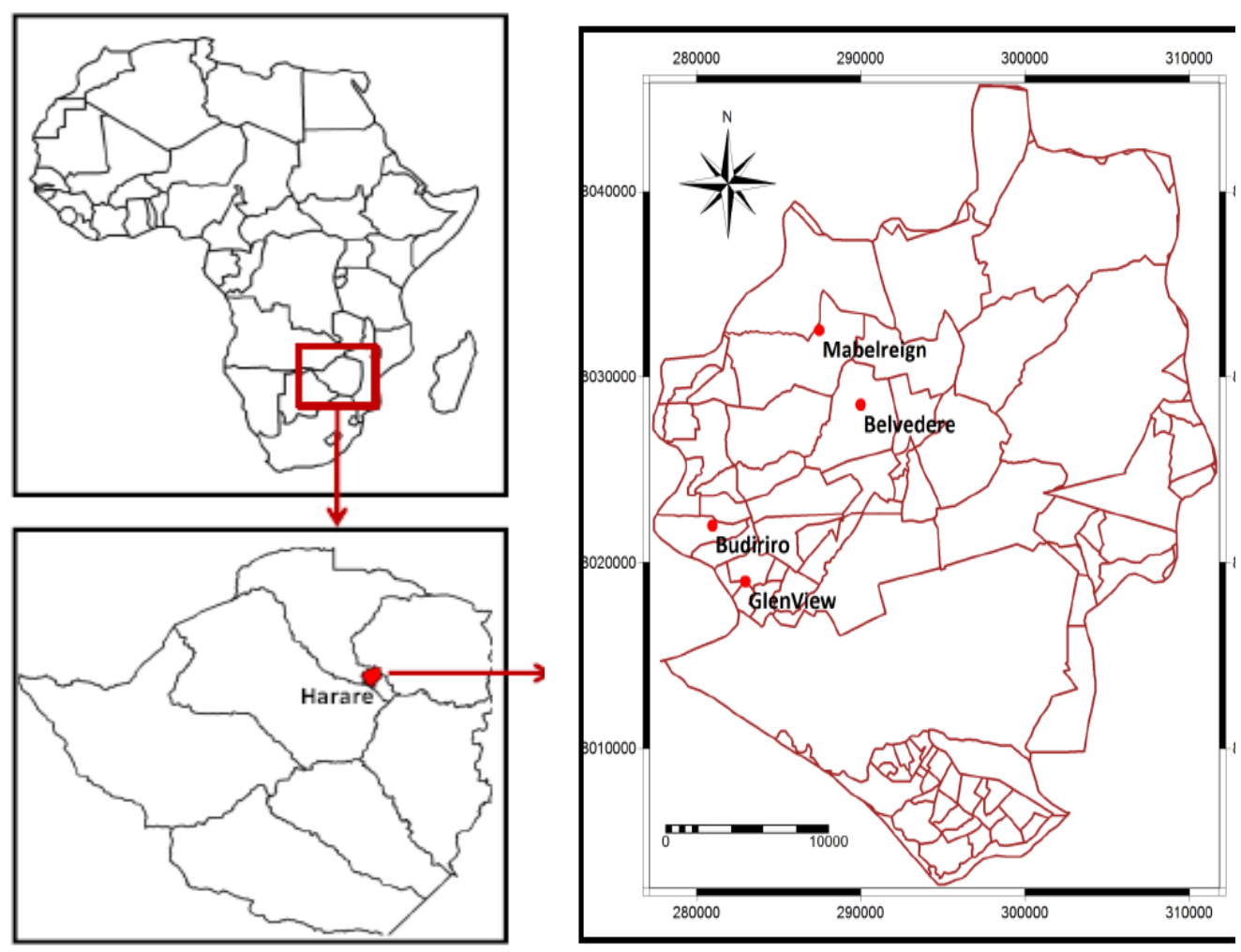

Figure 1 Map of Harare showing selected District Metered Areas (Ndunguru, 2012)

\section{Methodology}

\subsection{Data collection and experimental procedure}

Information about the water supply and network characteristics was obtained from the City of Harare's water utility, Harare Water. Water demand was obtained from flow logging campaigns that ran from $22^{\text {nd }}$ of April 2012 to the $5^{\text {th }}$ of May 2012 in all four DMAs. The flow logging was done over a 24-hour period in 15-minute intervals, meaning that 96 data sets were collected over 24 hours on each of the days. Therefore over the entire sampling period of 14 days, 1344 data sets were obtained. The data chosen was divided into three groups, the training group, corresponding to $70 \%$ of the data, the validation group representing $15 \%$ and the test group, which corresponds to $15 \%$ of data; so that the generalization capacity of network could be checked after the training phase. Furthermore, Matlab was used as a simulation tool; and the first step was loading the data and visualizing it then removal of 'abnormal' data was done for training the data. Comprehensive statistical analysis and data characterisation was done to help identify the boundaries of study domain as well as potential deficiencies in the data sets. The next step was the construction of training inputs and targets, and pre-processing for training inputs and targets. Then the Neural Network (NN) was constructed and training of the NN was done. This was followed by the testing of the Network Performance. Finally, the comparison of the simulated water flow and the actual flow was done followed by computation of the forecast accuracy. The lesser the error, the more the forecast accuracy. The number of neurons and layers were changed to achieve maximum accuracy and or retaining was done to obtain the best fit.

\subsection{Artificial Neural Network}

This study was based on Multi-Layer Perception which was trained and tested using DMA flow data. The objective was to develop an ANN-based model using flow data generated by flow loggers in selected MDAs in Harare, Zimbabwe.

\subsubsection{Building the network}

In building the network, the designer specified the number of hidden layers, neurons in each layer, transfer function in each layer, training function, weight/bias learning function, and performance function. The development of optimal network architecture was done using the graphical user interface of Matlab, and validation of the water flows. Input vectors were placed in a matrix of concurrent vectors and one output flow variation over a 24-hour period. The five day flow logging data (22 April-26 April 2012) was computed in the following manner: 


$$
\left\{\mathrm{P}_{1}, \mathrm{t}_{1}\right\},\left\{\mathrm{P}_{2}, \mathrm{t}_{2}\right\}, \ldots,\left\{\mathrm{P}_{\mathrm{q}}, \mathrm{t}_{\mathrm{q}}\right\}
$$

where $P_{i}$ is the $i^{\text {th }}$ input to the network, and $t_{q}$ is the corresponding target output (Parida et al., 2006) the summarised data is in Table 2. The outputs were compared with target outputs as the inputs were applied to the network. A learning rule (trainlm algorithm) was used to adjust the weights and biases to nodes of the network in order to find the optimum network architecture that could map the input vectors to the target output vectors (i.e. with outputs as close to targets as possible). For the learning algorithm, the feed-forward back-propagation algorithm was used. Regarding the transfer functions, the log-sigmoidal transfer function was used. This transfer function is commonly used with the back propagation networks for most of time dependent problems and also because it is differentiable and gives the network the needed ability to learn and or model non linearity between input(s) and output(s). The output layer neuron however used purelin transfer function so that the outputs can take any value between negative and positive infinity meaning that no scalings are needed on the outputs.

\subsubsection{Training the network}

In network building several configurations were tried and the one with the "best" prediction efficiency was chosen to be used in network training and testing. The weights were adjusted in order to make the actual outputs (predicated) close to the target (measured) outputs of the network. In this study, flow logging data from one DMA (Budiriro - 22 April-26 April 2012) was used as input data while flow logging data from another DMA (Belvedere - 22 April 2012) was the target data. The actual outputs (predicted results) are shown in Table 1.

\subsubsection{Testing the network}

The next step was to test the performance of the developed ANN model. Data from another DMA (Belvedere 22 April - 26 April 2012) was used. In order to evaluate the performance of the developed ANN model quantitatively and verify whether there is any underlying trend in performance of ANN model, statistical analysis involving the coefficient of determination $\left(\mathrm{R}^{2}\right)$, and the root mean square error (RMSE) was conducted. RMSE provides information on the short term performance which is a measure of the variation of predicated values around the measured data. The lower the RMSE the more accurate is the estimation.

\subsection{Leakage detection by comparing measured water supply and predicted water demand}

In order to detect leakage a Matlab based algorithm (the optimal ANN model) was developed based on a continuous comparison between the measured water supply from flow logging data and the predicted water demand in a district metered area. The predicted water demand was compared with the DMA water consumption (figure obtained from metering), the difference of which represents water lost. It was assumed that water was lost through leakages and any other means were insignificant.

\section{Results and Discussion}

Table 1 shows the statistical analysis of the inputs and target data used in the ANN for network training. The table shows summarised flow logging data for Budiriro and Belvedere in terms of the mean, the maximum and the minimum flows.

Table 1 Statistical data for Budiriro and Belvedere DMAs used in ANN model

\begin{tabular}{|l|l|l|l|l|}
\hline & Date & Mean $\left(\mathrm{m}^{3} / \mathrm{h}\right)$ & $\operatorname{Max}\left(\mathrm{m}^{3} / \mathrm{h}\right)$ & $\operatorname{Min}\left(\mathrm{m}^{3} / \mathrm{h}\right)$ \\
\hline \multirow{4}{*}{$\begin{array}{l}\text { Inputs) } \\
\text { Budiriro }\end{array}$} & $22 / 04 / 12$ & 336 & 449 & 83 \\
\cline { 2 - 5 } & $23 / 04 / 12$ & 195 & 346 & 82 \\
\cline { 2 - 5 } & $24 / 04 / 12$ & 157 & 379 & 81 \\
\cline { 2 - 5 } & $25 / 04 / 12$ & 160 & 432 & 81 \\
\cline { 2 - 5 } & $26 / 04 / 12$ & 207 & 429 & 80 \\
\hline \multirow{4}{*}{$\begin{array}{c}\text { Targets) } \\
\text { Belvedere }\end{array}$} & $22 / 04 / 12$ & 274 & 383 & 29 \\
\cline { 2 - 5 } & $2304 / 12$ & 200 & 449 & 80 \\
\cline { 2 - 5 } & $24 / 04 / 12$ & 157 & 346 & 48 \\
\cline { 2 - 5 } & $25 / 04 / 12$ & 132 & 250 & 47 \\
\cline { 2 - 5 } & $26 / 04 / 12$ & 160 & 387 & 81 \\
\hline
\end{tabular}

In the case study the prediction algorithm (the optimal network) was run using the original flow logging data (model input data) and compared with the actually measured data. Table 3 shows the network configurations, network performance, and prediction accuracy of the network function. 


\subsection{Network architecture}

After trying several configurations, the optimum network architecture developed was based on one input layer and one hidden layer with twenty neurons using the training algorithm (trainlm) with early stopping. With early stopping data were divided as $70 \%$ training, $15 \%$ validation and $15 \%$ testing. To avoid over fitting more data sets were used. The training was stopped when the validation error increases for some specified and or default number of iterations. The weights and biases at the minimum of the validation error are returned finally. The network converged after 11 epochs with a mean square error (MSE) of 0.055 for training the subset. Also, through principal component analysis all the input variables were retained at 0.001 confidence level. This gave the best optimisation of the performance function with the least MSE. The output flow obtained though simulation (by the developed network) was found to have a very good correlation with the target flow at 0.997.

The mean daily volumes of water into the Budiriro DMA are shown in Table 2. The table shows the 1-20-1 ANN model, the actual model inputs, the model simulated outputs and a mean percentage prediction deviation of $0.39 \%$. Thus Table 2 shows the mean value of the modelled flows into the DMA. With a mean simulation efficiency of $99.61 \%$, it can be inferred that the model is quite efficient in modelling the daily ( 24 hours) flow dynamics of the water entering the DMA.

Table 2 Network configuration, actual inputs and simulated outputs

\begin{tabular}{|c|c|c|c|}
\hline \multicolumn{4}{|c|}{ Budiriro DMA } \\
\hline $\begin{array}{c}\text { Configuration: } \\
1-20-1\end{array}$ & & Model & $\begin{array}{c}\text { Mean Deviation } \\
0.39 \%\end{array}$ \\
\hline Date & Actual Inputs $\left(\mathrm{m}^{3}\right)$ & Simulated outputs $\left(\mathrm{m}^{3}\right)$ & $\%$ Deviation \\
\hline $22 / 04 / 12$ & 15898 & 15966 & 0.42 \\
\hline $23 / 04 / 12$ & 19385 & 19421 & 0.19 \\
\hline $24 / 04 / 12$ & 15402 & 15349 & 0.33 \\
\hline $25 / 04 / 12$ & 19352 & 19275 & 0.39 \\
\hline $26 / 04 / 12$ & 18105 & 18217 & 0.62 \\
\hline
\end{tabular}

The mean daily volumes of water entering the Belvedere DMA are shown in Table 3. The simulated outputs deviated from the mean by $0.36 \%$, thus showing a simulation efficiency of $99.64 \%$

Table 3 Network configuration, actual inputs and simulated outputs

\begin{tabular}{|c|c|c|c|}
\hline \multicolumn{4}{|c|}{ Belvedere DMA } \\
\hline $\begin{array}{c}\text { Configuration: } \\
1-20-1\end{array}$ & \multicolumn{2}{|c|}{ ANN Model } & Mean Deviation \\
\hline Date & Actual Inputs $\left(\mathrm{m}^{3}\right)$ & Simulated outputs $\left(\mathrm{m}^{3}\right)$ & \% Deviation \\
\hline $22 / 04 / 12$ & 16099 & 16163 & 0.40 \\
\hline $23 / 04 / 12$ & 19619 & 19668 & 0.25 \\
\hline $24 / 04 / 12$ & 26587 & 26703 & 0.44 \\
\hline $25 / 04 / 12$ & 12698 & 12733 & 0.28 \\
\hline $26 / 04 / 12$ & 15201 & 15268 & 0.44 \\
\hline
\end{tabular}

Table 4 shows the computation of the leakage detection using simulated water consumption by the Budiriro DMA. The difference between the simulated water consumption and the actual metered consumption represents the water leakage.

Table 4 Network configuration, actual and simulated demands

\begin{tabular}{|c|c|c|c|}
\hline $\begin{array}{c}\text { Model } \\
1\end{array}$ & $\begin{array}{c}\text { Configurations } \\
1-20-1\end{array}$ & $\begin{array}{c}\text { MSE } \\
0.055\end{array}$ & 0.97 \\
\hline \multicolumn{4}{|c|}{ Budiriro DMA } \\
\hline & $\begin{array}{c}\text { Actual Metered } \\
\text { Consumption }\left(\mathrm{m}^{3}\right)\end{array}$ & $\begin{array}{c}\text { Simulated Water } \\
\text { Consumption }\left(\mathrm{m}^{3}\right)\end{array}$ & \% Difference \\
\hline Figure 3 & 15073 & 15966 & 5.6 \\
\hline Figure 4 & 19241 & 19421 & 0.9 \\
\hline Figure 5 & 15393 & 15349 & 0.3 \\
\hline Figure 6 & 19834 & 19275 & 2.8 \\
\hline Figure 7 & 18488 & 18217 & 1.5 \\
\hline
\end{tabular}

Thus, Table 4 shows an average of $2.2 \%$ difference from the actual water consumption (metering value) indicating that $2.2 \%$ of the water supplied to the Budiriro DMA was lost through leakages from 22 April 2012 to 26 April 2012. Figure 3, 4, , 5, 6 and 7 
show the graphs of the actual water demand obtained from flow logging data and the predicted flows obtained from testing the ANN.

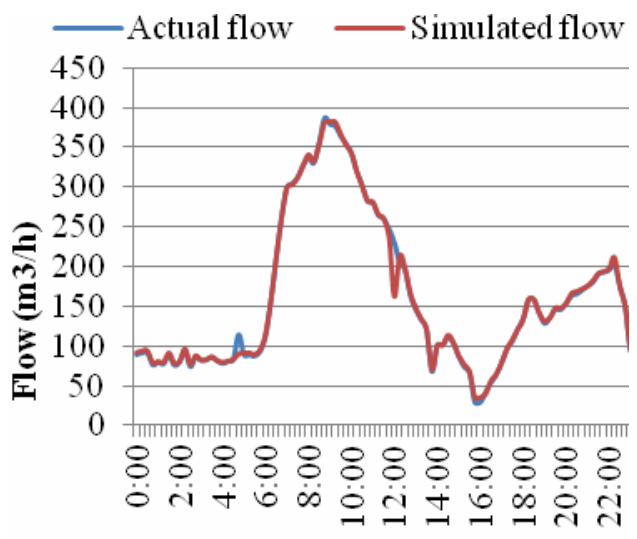

Time of day

Figure 3 Actual flow and simulated flow (22/04/12)

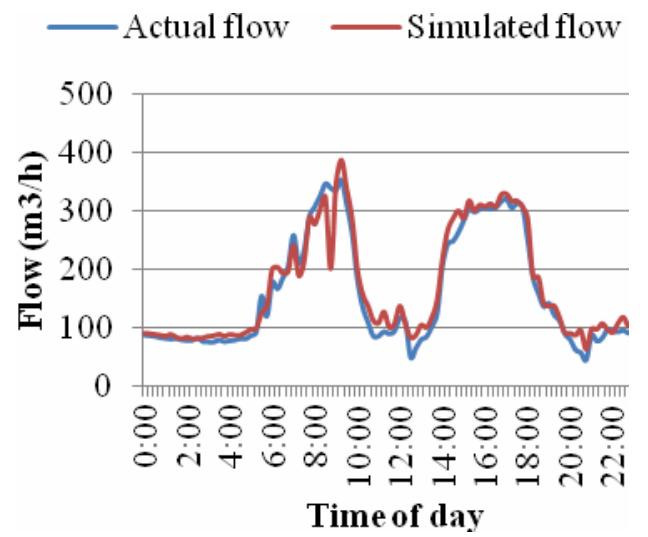

Figure 5 Actual flow and simulated flow (24/04//12)

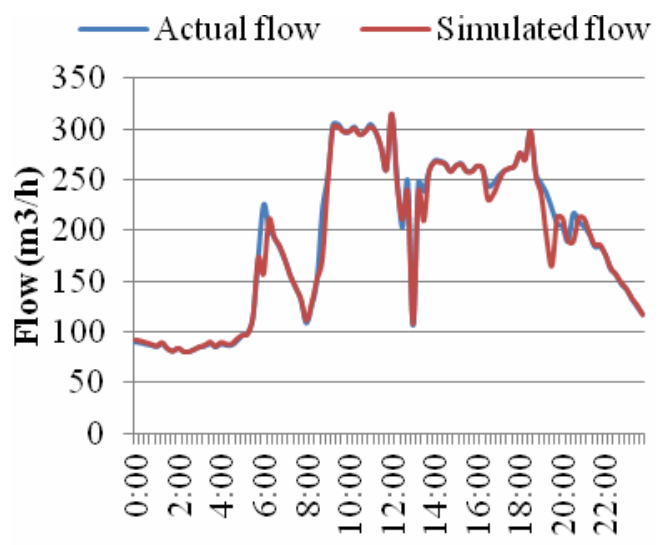

Time of day

Figure 7 Actual flow and simulated flow (26/04/12)

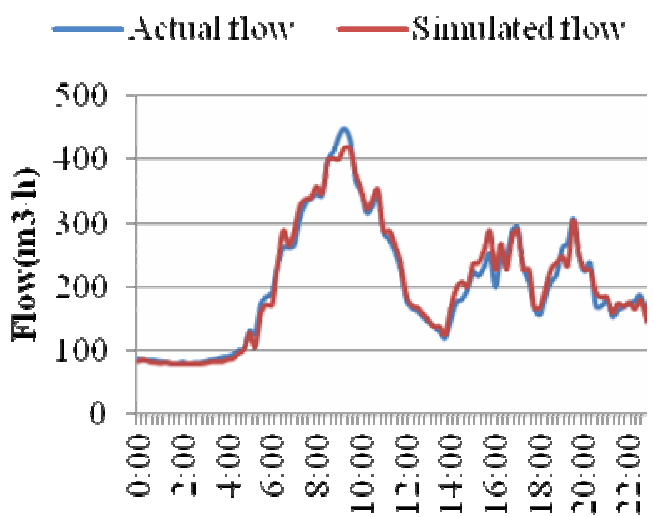

Time of day

Figure 4 Actual flow and simulated flow (23/04/12)

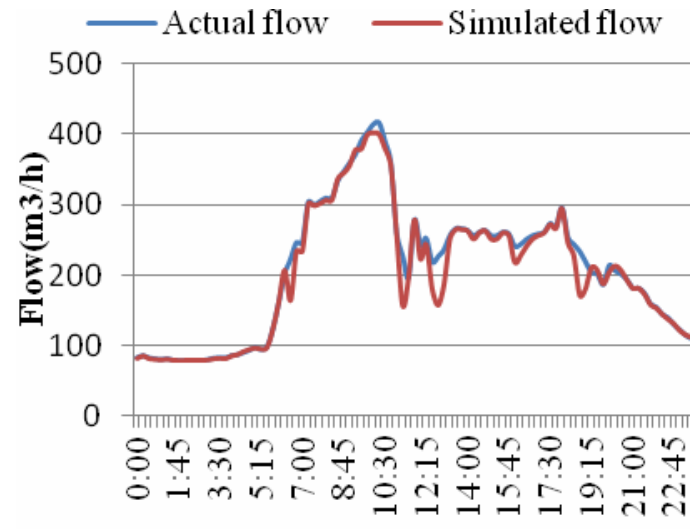

Time of day

Figure 6 Actual flow and simulated flow (25/04/12) 
Table 5 summarises the water actual metered consumption and the simulated water consumption in the Belvedere DMA over the period 22 April to 26 April 2012.

Table 5 Network configuration, actual metered consumption and simulated water consumption

\begin{tabular}{|c|c|c|c|}
\hline $\begin{array}{c}\text { Model } \\
1\end{array}$ & $\begin{array}{c}\text { Configurations } \\
1-20-1\end{array}$ & $\begin{array}{l}\text { MSE } \\
0.055\end{array}$ & $\begin{array}{c}\mathrm{R}^{2} \\
0.97\end{array}$ \\
\hline \multicolumn{4}{|c|}{ Belvedere DMA } \\
\hline & $\begin{array}{c}\text { Actual Metered } \\
\text { Consumption }\left(\mathrm{m}^{3}\right)\end{array}$ & $\begin{array}{c}\text { Simulated Water } \\
\text { Consumption }\left(\mathrm{m}^{3}\right)\end{array}$ & \% Difference \\
\hline Figure 8 & 15417 & 16163 & 4.6 \\
\hline Figure 9 & 19241 & 19668 & 2.2 \\
\hline Figure 10 & 26346 & 26703 & 1.3 \\
\hline Figure 11 & 12695 & 12733 & 0.3 \\
\hline Figure 12 & 15074 & 15268 & 1.3 \\
\hline
\end{tabular}

Figure 8, 9, 10, 11 and 12 show the actual metered consumption (actual flow) and the simulated water consumption (Simulated flow) for the Belvedere DMA. The percentage difference between the actual metered consumption and the simulated water consumption represents the water lost through leakages. Thus over the 5 day period an average of $1.94 \%$ of the water supply to the DMA was lost through leakage.

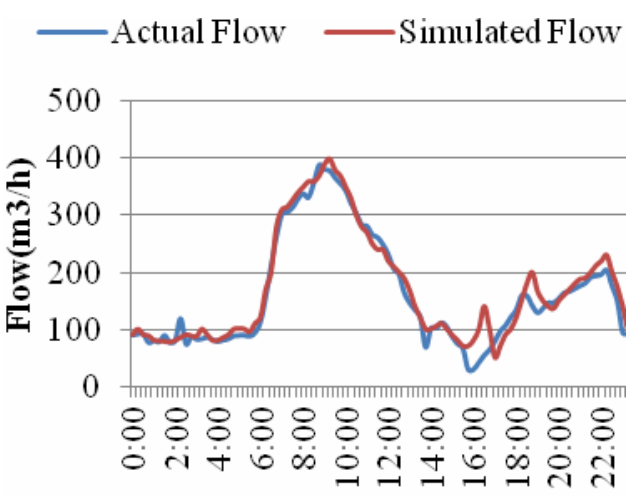

Time of day

Figure 8 Actual flow and simulated flow (22/04/12)

-Actual Flow $\longrightarrow$ Simulated Flow

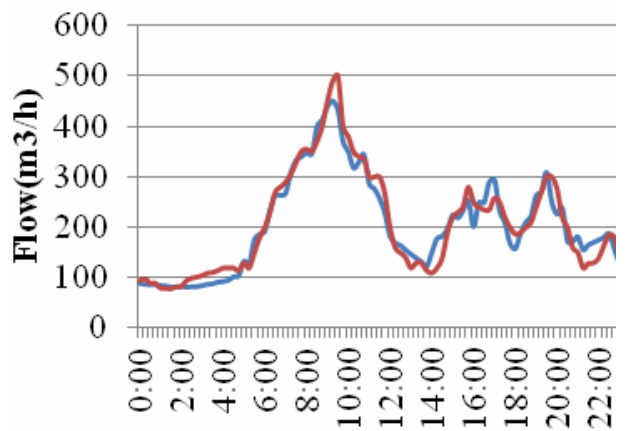

Time of day

Figure 9 Actual flow and simulated flow (23/04/12)

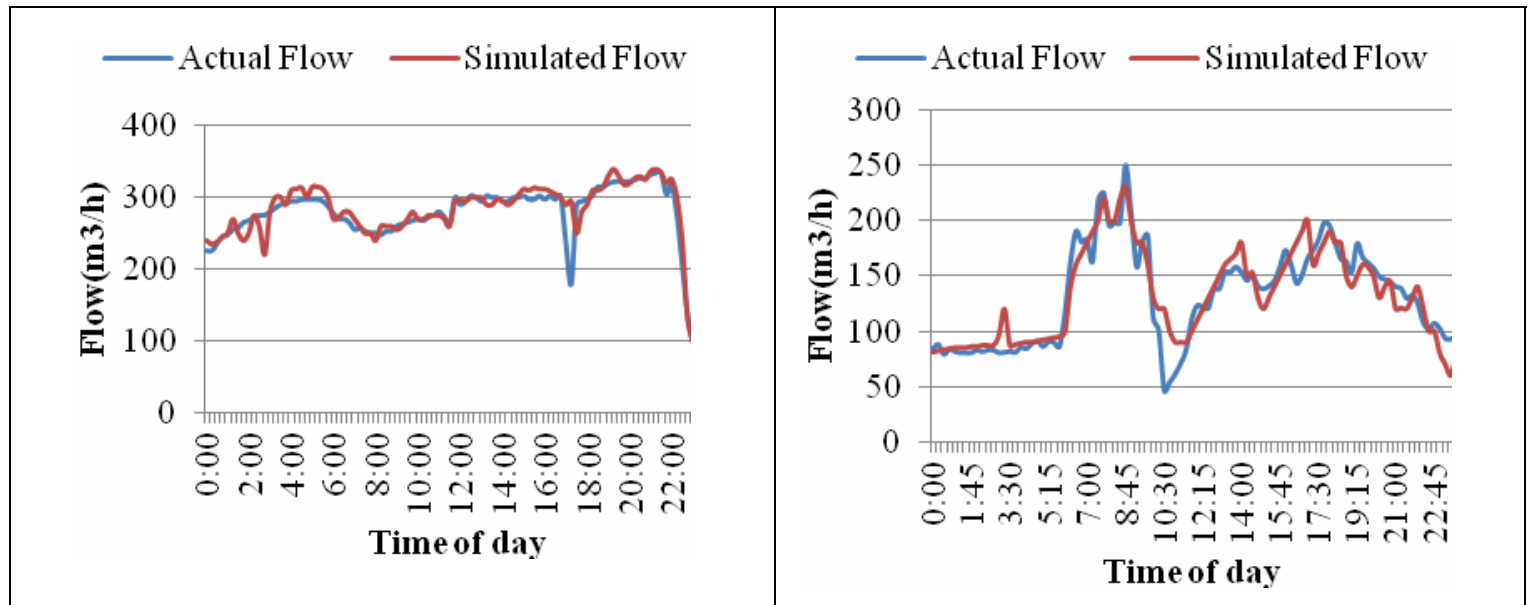

Figure 10 Actual flow and simulated flow (24/04/12)

Figure 11 Actual flow and simulated flow (25/04/12) 


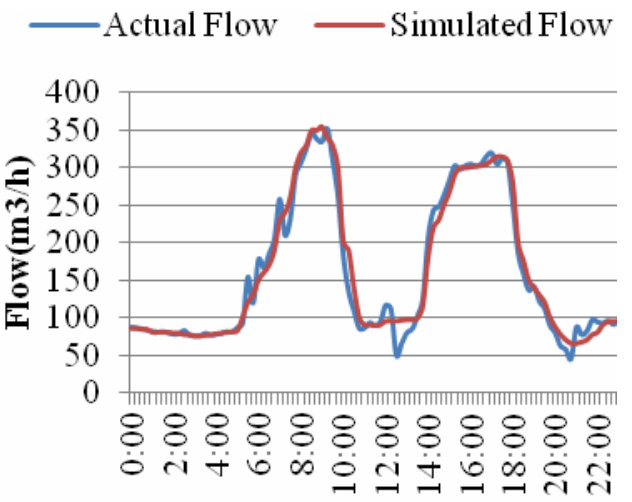

Time of day

Figure $12 \quad$ Actual flow and simulated flow (26/04/12)

Figure 13 shows the graphs of actual water demand versus predicted demand of the City of Harare for the period January 2009 to December 2011. The percentage leakage represents the percentage difference between the actual water consumption (according to DMA metering) and the predicted water demand according to the developed ANN model. The average actual water consumption is 16.1 million litres per month and the simulated average water demand is 10.8 million litres per month. The difference represents an average water leakage of 33\%. This leakage result is consistent with the estimated leakage value of $36 \%$ for the City of Harare (City of Harare, 2011).Thus, the developed ANN model for modelling flow into a DMA and the leakage model (simulated water demand less metered water consumption) are quite effective and efficient tools for water utilities to understand and assess the water losses in their water distribution networks.

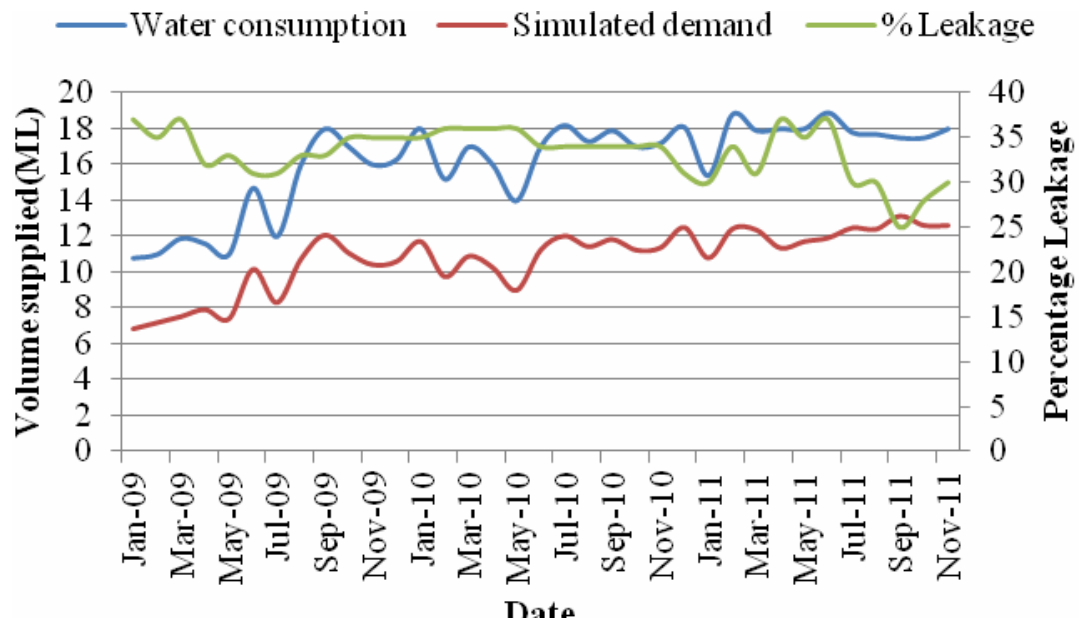

Figure 13 Percentage leakages from January 2009 to December 2011

\section{Conclusions and recommendations}

A feed-forward ANN model using back-propagation was developed to simulate flow within four DMAs of the City of Harare. The results show that an appropriate (99\%) simulation accuracy can be achieved using this network. It is therefore concluded that the neural network approach for modelling flow dynamics is capable of yielding good results and can be considered as an alternative to traditional flow logging approaches. Furthermore, the developed methodology can be used to detect leakages in the water distribution networks with good precision. The ANN model is peculiar in that it can detect small leakages of less than $5 \%$. The developed methodology is compact, adaptable, cost effective and simple to apply. Thus, the weaknesses of the traditional flow logging approaches entailing data collection costs and time delays as well as data handling errors, are therefore offset. In spite of the achieved milestone, the work can be further extended to predict pressure dynamics in water distribution networks and hence background leakages. 


\section{Acknowledgements}

The authors acknowledge VolkswagenStiftung Foundation for funding this research and the City of Harare for the permission to carry out this study.

\section{References}

Abdul-Kader H. M. 2009. Neural networks training based on differential evolution algorithm compared with other architectures for weather forecasting. International Journal of Computer Science and Network Security, Vol. 9 No.3, pp. 92-99.

Achim, D., Ghotb, F., and McManus, K. J. 2007. Prediction of water pipe asset life using neural networks. Journal of Infrastructure Systems, Vol. 13, No. 1, p. 26-30.

Al-Barqawi, H., and Zayed, T. 2008. Infrastructure management: integrated AHP/ANN model to evaluate municipal water mains' performance. Journal of Infrastructure Systems, Vol. 14, No. 4, p. 305-318.

Al Shamisi, M H.,. Assi, A.H and Hejase, H. A. N. 2011. Using MATLAB to Develop Artificial Neural Network Models for Predicting Global Solar Radiation in Al Ain City - UAE, Engineering Education and Research Using MATLAB

Asnaashari, A., McBean, E. A., Shahrour, I., and Gharabaghi, B. 2009. Prediction of water main failure frequencies using multiple and Poisson regression. Water Science \& Technology: Water Supply, Vol. 9, No. 1, p. 9-19.

Bakker M, Van Schagen KM and Timmer J. 2003. Flow control by prediction of water demand. Journal of Water Supply: Research and Technology-AQUA Vol. 52, No. 6, pp. 417-424.

Bicik J, Kapelan Z, Makropoulos C and Drasavic G. A. 2011. Pipe burst diagnostics using evidence theory. Journal of Hydroinformatics, Vol. 13, No. 4, pp. 596-608.

Bose N K and Liang P. 1998. Neural Network Fundamentals with Graphs, Algorithms and Applications. Tata McGraw-Hill, pp. 478.

Chiipanthenga M. M. 2008. Investigation of the suitability of simple and rapid techniques for leakage management in water distribution systems: A case of Blantyre water supply area, Malawi, M.Sc. Thesis, and University of Zimbabwe.

Chipwaila J. A. 2009. Partitioning of unaccounted for water for Zomba city water supply system in Malawi. M.Sc. Thesis, University of Zimbabwe.

Ferziger J.H. and Peric M. 1996. Computational Methods for Fluid Dynamics, Springer Verlag, New York.

Jafar, R., Shahrour, I., and Juran, I. 2010. Application of artificial neural networks (ANN) to model the failure of urban water mains. Mathematical and Computer Modelling, Vol. 51, No. (9-10), pp.1170-1180.

Kleiner, Y., and Rajani, B. 2001. Comprehensive review of structural deterioration of water mains: Statistical models. Urban Water, Vol. 3, No. 3, pp. 131-150.

Maggs, I., 2005. Hydraulically flow modulated pressure control - is this the way forward? water services, Association of Australia Journal, No. 3, May, pp. 12-19.

Mazvimavi D, Maijerink AMJ, Savenije HHG, and Stein A. 2005. Prediction of flow characteristics using multiple regression and neural networks; a case study in Zimbabwe. Physics and Chemistry of the Earth Vol. 30, pp.639-647.

McKenzie, R.S., 2001. PRESMAC User Guide. South Africa Water Research Commission, WRC Report TT 152/01, Pretoria, South Africa.

Mounce S R, Day A J, Wood A S, Khan A, Widdop P D and Machell J. 2002. A neural network approach to burst detection. Water Science and Technology, Vol. 45, No. 4-5, pp. 237-246.

Mounce, S. R., Khan, A., Wood, A. S., Day, A. J., Widdop, P. D., and Machell, J. 2003. Sensor-fusion of hydraulic data for burst detection and location in a treated water distribution system. Information Fusion, Vol. 4, No. 3, pp. 217-229.

Mounce, S. R., and Machell, J. 2006. Burst detection using hydraulic data from water distribution systems with artificial neural networks. Urban Water Journal, Vol. 3, No. 1, pp. 21-31.

Mounce, S. R., and Boxall, J. B. 2010. Implementation of an online artificial intelligence district meter area flow meter data analysis system for abnormality detection: A case study. Water Science and Technology: Water Supply, Vol. 10, No. 3, pp. 437444.

Mounce, S. R., Mounce, R. B., and Boxall, J. B. 2011. Novelty detection for time series data analysis in water distribution systems using support vector machines. Journal of Hydroinformatics, Vol. 13, No. 4, pp. 672- 686.

Ndunguru, M.G. 2012. Assessment of non-revenue water management in Harare-Zimbabwe, MSc Thesis, University of Zimbabwe, Harare, Zimbabwe.

Nishiyama, M., and Filion, Y. 2013. Forecasting water main failure using artificial neural network and generalized linear models. World Environmental and Water Resource Congress 2013: 15th Annual Water Distribution System Analysis Symposium.

Paras S M, Kumar A and Chandra M. 2007. A feature based neural network model for weather forecasting. World Academy of Science, Engineering and Technology, p. 34.

Parida B P, Moalafhi D B and Kenabatho P. K. 2006. Forecasting runoff coefficients using ANN for water resources management: The case of Notwane catchment in Eastern Botswana, Physics and Chemistry of the Earth Vol. 31, pp. 928-934 
Puust, R., Kapelan, Z., Savic, D. A., and Koppel, T. 2010. A review of methods for leakage management in pipe networks. Urban Water Journal, Vol. 7, No. 1, pp. 25-45.

Shamseldin A. Y. 1997. Application of neural network technique to rainfall-runoff modelling. Journal of Hydrology Vol. 199, pp. 272-294

Tesfamariam, S., Rajani, B., and Sadiq, R. 2006. Possibilistic approach for consideration of uncertainties to estimate structural capacity of ageing cast iron water mains, 064 (December), pp. 1050-1064.

The Mathworks Inc., 2002. Neural Network Toolbox; for use with MATLAB, User's guide Version 4

Zadeh, L. A. 1994. Soft computing and fuzzy logic. Software, IEEE, (November).

\section{Biographical notes}

Oliver Hensel is Full Professor (C4) for Agricultural Engineering at the Faculty of Organic Agricultural Sciences at the University of Kassel since 2004; Founder Member of the International Centre for Decent Work and Development - "Higher Education Excellence in Development Co-operation" by DAAD and the German Federal Ministry for Economic Cooperation and Development (BMZ). Areas of Expertise: Postharvest Technology, Renewable Energy, Tillage, Irrigation, Rural Development, Sensors for Farm Implements.

Eugine Makaya is a Doctoral candidate in the Department of Agricultural Engineering, Faculty of Organic Agriculture, University of Kassel, Germany. He is a holder of a Master of Science degree in Water Resources Engineering and Management from the University of Zimbabwe. His main Research interests are in Water loss Management, Water supply and sanitation and Hydro-informatics.

Received May 2014

Accepted September 2014

Final acceptance in revised form November 2014 